\title{
(息)
}

Citation:

Bagnall, A and White, $J$ and South, J (2017) Community engagement: what the NICE guidance means for community practitioners. Primary Health Care. ISSN 0264-5033 DOI: https://doi.org/10.7748/phc.2017.e1192

Link to Leeds Beckett Repository record:

https://eprints.leedsbeckett.ac.uk/id/eprint/3487/

Document Version:

Article (Accepted Version)

The aim of the Leeds Beckett Repository is to provide open access to our research, as required by funder policies and permitted by publishers and copyright law.

The Leeds Beckett repository holds a wide range of publications, each of which has been checked for copyright and the relevant embargo period has been applied by the Research Services team.

We operate on a standard take-down policy. If you are the author or publisher of an output and you would like it removed from the repository, please contact us and we will investigate on a case-by-case basis.

Each thesis in the repository has been cleared where necessary by the author for third party copyright. If you would like a thesis to be removed from the repository or believe there is an issue with copyright, please contact us on openaccess@leedsbeckett.ac.uk and we will investigate on a case-by-case basis. 


\section{Title: Community engagement: what the NICE guidance means for community practitioners}

Authors: Anne-Marie Bagnall, Judith White, Jane South

Summary: This article draws on the updated guidance on community engagement from the National Institute of Health and Care Excellence (NICE 2016), and the evidence that informed that guidance, to discuss the role and potential of engaging with the community in primary care, to improve health and wellbeing. In practice, there are several different ways of engaging with communities, and practitioners need to choose the way that is the best fit with their project, community and ways of working. A guide to community centred approaches recently published by Public Health England and NHS England, maps the range of evidence based options, and two examples from the UK are used to illustrate different approaches to community engagement: one in which lay people from the community delivered a diabetes education project, and one in which volunteers worked with a specialist nurse to provide a holistic arthritis support service.

Key words: community engagement; volunteers; primary care; community practitioners

\section{Why is community engagement important in the health and social care system?}

NICE recognises the importance of involving people and communities in the design and delivery of health and care services and interventions to improve health and wellbeing. Community engagement has been defined as "the direct or indirect process of involving communities in decision making and/ or in the planning, design, governance and delivery of services, using methods of consultation, collaboration and/or community control" (O'Mara-Eves et al., 2013, p.6). Whilst the term community engagement covers a broad range of types of activities, at its heart is the process of people becoming actively involved in issues that affect their health. A recent systematic review of the international literature on community engagement to reduce inequalities in health O'Mara-Eves et al. (2013) grouped community engagement approaches for disadvantaged groups into three categories:

- Patient/ consumer involvement in development: engaging with communities, or members of communities, in strategies for service development, including consultation or collaboration with the community about the intervention design.

- Peer/ lay delivered interventions: services engaging communities, or individuals within communities, to deliver interventions. There is evidence that change is facilitated by the credibility, expertise or empathy that the community member can bring to the delivery of the intervention (South et al. 2013).

- Empowerment of the community: the health need is identified by the community and they mobilise themselves into action, rather than rely on professional facilitation.

There are various justifications for seeking to engage disadvantaged communities: - for example to support the identification of community needs and priorities, to improve services through hearing the perspective of users, or to mobilise community resources, especially people, in the delivery of activities. Underpinning community engagement is the belief that people have a right to participate in decisions about their community and their health. This approach is supported by policy, for example, one of the six principles endorsed by NHS England for their new models of care programme ${ }^{1}$ is that 'Services are created in partnership with citizens and communities' (Jones, 2015,

\footnotetext{
${ }^{1}$ https://www.england.nhs.uk/ourwork/futurenhs/new-care-models/support/empowering/
} 
p.6). Plus the process of community engagement may help to reduce health inequalities by improving social capital and reducing isolation in people in disadvantaged groups, thus meeting the Department of Health policy objective of 'improving the health of the poorest fastest' (Department of Health, 2012; Marmot 2010).

It has also been argued that the NHS needs more joined-up patient and public involvement and better engagement with local communities, with public engagement skills being built into mainstream management. This has the potential to lead to both more effective services, which are responsive to need, and to more support for the NHS from local people (Gamsu \& White, 2015).

\section{The NICE guidance on community engagement}

The National Institute for Health and Care Excellence (NICE) in the UK issued guidance on community engagement for public health practitioners in 2009 (NICE, 2009). While this provided useful evidence on the effectiveness of community engagement and made recommendations on how this should be done, it was noted that there was not much evidence published on the best ways to successfully engage with communities (i.e. the process of community engagement). In 2014, NICE's Centre for Public Health Excellence decided, as well as updating the evidence on effectiveness, to commission a new stream of work to explore current and emerging practice in community engagement in the UK. This gave the authors an opportunity to examine what was happening on the ground, rather than simply what had been published as research articles, and to enable communities to share their knowledge and experience about the process of what works for successful community engagement. The evidence underpinning the updated guidance included three systematic reviews of effectiveness, which looked at the international evidence in randomised controlled trials (Brunton et al, 2014; Brunton et al., 2015; Stokes et al., 2015), a systematic map of UK policy and practice (Bagnall et al., 2015a), a systematic review of barriers and facilitators to community engagement in the UK (Harden et al, 2015), a primary research report of UK case studies (Bagnall et al., 2015b), and four reports on cost-effectiveness (Dates et al. 2015; Optimity Advisers 2015a; Optimity Advisors 2015b; Optimity Advisors 2016).

The systematic review of the evidence on community engagement for disadvantaged groups (O'Mara-Eves et al., 2013) reported that public health interventions using community engagement for disadvantaged groups are effective in terms of health behaviours, health outcomes, participant self-efficacy and perceived social support outcomes. The authors suggested that community engagement requires a 'fit for purpose' rather than 'one size fits all' approach. The systematic reviews of effectiveness carried out for the updated NICE guidance (Brunton et al, 2014; Brunton et al. 2015; Stokes et al. 2015) found that higher levels of community engagement are linked to better health outcomes for disadvantaged groups.

For the UK-focused evidence, as well as searching for published research articles in electronic databases, we searched the websites of over 100 relevant organisations and put out a call for evidence through our established networks of public health and community practitioners, and through NICE. We found a lot of evidence in organisations' reports and evaluations (so-called "grey" literature) as well as in research journals.

Mapping the evidence in the UK (Bagnall et al. 2015a) we found that what was happening on the ground was not necessarily reflected in the published research literature: 
- The health and wellbeing issues addressed most commonly by UK community engagement initiatives were to do with improving community-level health or wellbeing, rather than individual behaviour change. This was a different pattern than the studies included in the systematic reviews of effectiveness (Brunton et al. 2016a; Brunton et al. 2016b; Stokes et al. 2016), which focused on individual health issues such as physical activity and healthy eating.

- Community engagement initiatives seek to engage some of the most marginalised, disadvantaged or excluded population groups, such as refugees and asylum seekers; LGBT+; people with mental health issues; people with substance use disorders; offenders and exoffenders.

- Different approaches were used to target different types of health or wellbeing issues, for example peer involvement was most often seen in interventions targeting individual behaviour change (e.g. physical activity, healthy eating, substance use), whereas strengthening communities or partnership approaches were more often seen in initiatives that focused on improving community wellbeing, social capital or community assets.

- Examination of trends over time (from 2000 to 2014) showed increases in approaches using peer involvement since 2009 and health advocacy approaches (such as health trainers) since 2007.

The systematic review of barriers and facilitators to community engagement in the UK (Harden et al. 2015) and the analysis of UK case studies (Bagnall et al. 2015b) also highlighted themes of trust within the community and between community members and service providers; respect for community members' expertise; allowing sufficient time for relationships to establish and for outcomes to be seen; commitment of key people; and flexibility.

The revised NICE guidance (NICE, 2016) drew on this evidence, recognising that building relationships, trust, commitment, leadership and capacity across local communities and statutory organisations needs time and that drawing on existing groups and networks is important. The guidance emphasises that to address health inequalities, additional efforts need to be made to involve communities at risk of poor health. This includes people who are vulnerable, marginalised, isolated or living in deprived areas. Working to ensure that community engagement is an integral part of health and wellbeing initiatives is vital for sustainability. As the overview in Figure 1 illustrates, to be effective community engagement has to be developed locally with an emphasis on developing partnerships to plan, design, develop, deliver and evaluate health and wellbeing initiatives collaboratively. Drawing on 'the knowledge and experience of local communities and community and voluntary organisations to identify and recruit people to take on peer and lay roles as part of the health and wellbeing initiative' (NICE 2016 1.3) is also central to the approach recommended by NICE, with an emphasis on making it as easy as possible for people to get involved. 
Figure 1: Community engagement pathway (NICE, 2016)

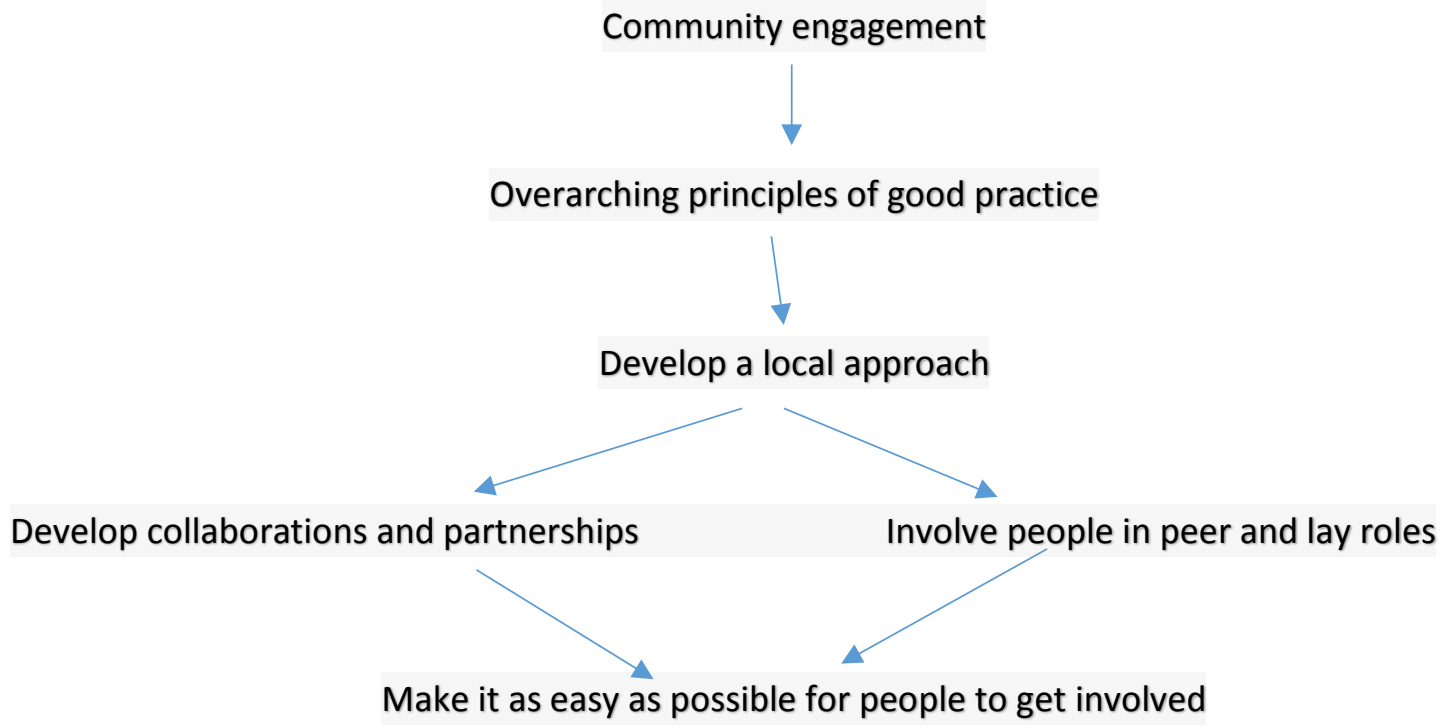

\section{What community engagement means in practice}

Community engagement can take many forms, and to help commissioners and practitioners make sense of the range of potential activities Public Health England and NHS England issued a guide to community-centred approaches for health and wellbeing in 2015, which outlined a family of approaches to engaging communities which were relevant to UK practice (PHE, NHSE 2015). These were grouped into four main categories:

- Strengthening communities: where approaches involve building on community capacities to take action together on health and the social determinants of health;

- Volunteer and peer roles: where approaches focus on enhancing individuals' capabilities to provide advice, information and support or organise activities around health and wellbeing in their or other communities;

- Collaborations and partnerships: where approaches involve communities and local services working together at any stage of the planning cycle, from identifying needs through to implementation and evaluation;

- Access to community resources: where approaches connect people to community resources, practical help, group activities and volunteering opportunities to meet health needs and increase social participation.

The family of community-centred approaches is a simple tool that maps the range of evidence-based options. Health professionals can use this to start to select what type of community engagement approach might work best in what context, as the NICE guidance on community engagement (NICE 2016) recommends. The guide also suggests other resources where they can find more information. Working in a community-centred way is not just about services being based in a community, it is about valuing what communities can contribute to improving health, whether that is through the specific skills and local knowledge of community members or through community organisations and groups. 
Sometimes community practitioners will be able to initiate engagement, but often a really valuable role is to work in partnership with other services and organisations where they can be a credible source of support and advice in local communities. How community nurses in particular can be central to engagement at different levels is illustrated by two examples (see boxes 2 and 3). Both examples are illustrative of volunteer and peer roles, one of the four strands of community centred approaches identified above (PHE, NHSE 2015).

The first is from a diabetes education programme called "Sadee Smile" which was delivered by nonclinical tutors drawn from the South Asian communities at which the programme was aimed. The second is "Living Well with Arthritis", which is delivered by volunteers with arthritis. Both illustrate how community practitioners can work in partnership with voluntary sector organisations to engage communities for the benefit of those communities and their own practice.

\section{Box 1: Sadee Smile}

Sadee (Our) Smile is a course on living with diabetes specifically designed for South Asian communities. Four weeks on self-management are followed by four cook and eat sessions where participants prepare healthy meals together. The course was delivered in Leeds by non-clinical tutors of South Asian origin, who were trained by the Lead Dietician who designed the course and supported by a Diabetes Nurse who delivered the third session of which covered the more clinical aspects such as medication. An evaluation of the pilot (11 courses run in community venues in some of the poorest parts of Leeds) found that the course was very popular with participants and led to improvements in knowledge and confidence and changes in lifestyle. Tutors said that the input from the nurse brought home the seriousness of the condition - particularly important as, 'diabetes amongst our community is so common now that it's just like yeah you take it for granted'(White and Coan 2016 p 17). As well as explaining diabetes the nurse told them what health care they should expect. The Lead Dietician who supported the course commented on the improvement in understanding and felt the course had empowered people to ask for example, for regular urine and eye tests. At least one person had changed their GP having learnt what support they were entitled to. Participants particularly liked that the course was run in their languages, in venues accessible to them and that it was in groups and culturally appropriate. The specialist nurse agreed that providing education in group settings worked well saying 'they sort of bounced off each other and shared things so I think that was good'(White and Coan $2016 \mathrm{p} \mathrm{15)}$

\section{Box 2: Living Well with Arthritis}

A Rheumatology Nurse Practitioner based in Gateshead, works very closely with the charity Arthritis Care (AC) who she views as invaluable partners in providing a range of services - one of which is Living Well with Arthritis. Through this programme volunteers who have arthritis themselves have been trained to run regular drop in events offering support, guidance and practical information to help people to deal with the physical and emotional impact of living with arthritis. As well as a drop in there is one to one peer support on offer, community workshops and exercise and activity classes. The Nurse Practitioner attends meetings of her local AC group on a regular basis and recently worked with them to organise a local patient conference with 130 attendees. She sees the work of $\mathrm{AC}$ as an invaluable complement to the work of her team in the hospital. They aim to provide the best clinical care possible but to live well with arthritis people need social and psychological help too - which comes best from those who are also living with the condition. One of the crucial aspects of AC's role she sees as 'encouraging self-management, with patients supporting each other and being 
aware when to sign post to others'. AC have support groups for all types of arthritis, including for people with osteoarthritis and fibromyalgia for whom there is little in the way of clinical interventions. Gateshead AC also support a group for patients using Gateshead rheumatology and pain service From the specialist nurse's perspective is all about partnership to improve care 'working together can only benefit the people we are looking after.'

Note: the quotes are taken from a presentation given by the practitioner and were verified by email.

As outlined above there are many approaches to community engagement and one of the challenges is to link for example volunteer involvement in service delivery as illustrated by these examples to other forms of community engagement such as user representation on Trust Boards, rather than these being organised separately (White and Gamsu 2015).

\section{Community engagement for practitioners: key points}

Community practitioners need to:

- Make use of the variety of approaches to community engagement described in the PHE guide (2015).

- Identify and work with community networks and organisations, particularly those reaching vulnerable groups or recently established communities

- Encourage local communities to get involved in all stages of a health and wellbeing initiative from setting priorities to delivering interventions.

- Be clear about which decisions community members can influence, and how this will happen - avoid tokenistic involvement.

- Work with local communities and community and voluntary organisations to identify barriers to involvement, particularly for vulnerable groups and recently established communities, and the best ways to communicate with these groups

\section{Conclusion}

Community engagement is about 'doing with', rather than 'doing to' communities, empowering them to take control of their own health and wellbeing, and is associated with better health outcomes and reduced health and social inequalities for disadvantaged groups. The best outcomes come from the highest levels of engagement: where community members are involved in the design, delivery and evaluation of a service. To allow high levels of engagement, health and social care practitioners must work with the community to dismantle practical and cultural barriers to participation, and commissioners must recognise that this process takes time and resources. The updated NICE guidance on community engagement provides practical recommendations, based on both research evidence and lived experience of community members and is thus a useful resource for community practitioners.

\section{Acknowledgements}


The Centre for Health Promotion Research was commissioned by NICE to undertake systematic mapping reviews of current and emerging community engagement practice in the UK, to inform the updated guidance. The views and opinions expressed herein are those of the authors and do not necessarily reflect those of NICE.

The reviews were undertaken in partnership with the Institute of Health and Human Development at the University of East London

The authors would like to thank Jacqui Binding, Rheumatology Nurse Practitioner with Queen Elizabeth Hospital in Gateshead and Alison Cawthorne and Hilary Wolstenholme, Clinical Lead Diabetes Dietitians and Diabetes Nurse respectively with Leeds Community Healthcare NHS Trust, for their contributions to the case studies.

Anne-Marie Bagnall is a Reader in Evidence Synthesis (Health Inequalities) at the Centre for Health Promotion Research, Leeds Beckett University

Jane South is a Professor of Healthy Communities at the Centre for Health Promotion Research, Leeds Beckett University

Judy White is a Senior Lecturer in Health Promotion, and Director of Health Together, at Leeds Beckett University

\section{References}

Bagnall AM, South J, Trigwell J, Kinsella K, White J, Harden A (2015a) Community engagement approaches to improve health: Map of the literature on current and emerging community engagement policy and practice in the UK. Leeds: Centre for Health Promotion Research, Institute for Health and Wellbeing, Leeds Beckett University.

Bagnall AM, Kinsella K, Trigwell J, South J, Sheridan K, Harden A (2015b) Community engagement approaches to improve health: Map of current practice based on a case study approach. Leeds: Centre for Health Promotion Research, Institute for Health and Wellbeing, Leeds Beckett University.

Brunton G, Caird J, Stokes G, Stansfield C, Kneale D, Richardson M, Thomas J (2014) Review 1: Community engagement for health via coalitions, collaborations and partnerships - a systematic review. London: EPPI-Centre, Social Science Research Unit, Institute of Education, University of London.

Brunton G, Caird J, Kneale D, Thomas J, Richardson M (2015) Review 2: Community engagement for health via coalitions, collaborations and partnerships: a systematic review and meta-analysis. London: EPPI-Centre, Social Science Research Unit, Institute of Education, University of London.

Dates M, Mallender J, Pritchard C, Rtveladze K (2015) Community engagement - approaches to improve health and reduce health inequalities. Review of Social Return on Investment (SROI) evaluations. Health Economics 4-SROI. Optimity Advisors.

Department of Health (2012) Healthy Lives, Healthy People: our strategy for public health in England. London: Her Majesty's Stationary Office 
Gamsu M, White J (2015) Move patient and public involvement from the margins to the mainstream. Health Services Journal, 11 December, 2015

Harden A, Sheridan K, McKeown A, Dan-Ogosi I, Bagnall AM (2015) Evidence Review of Barriers to, and Facilitators of, Community Engagement Approaches and Practices in the UK. London: Institute for Health and Human Development, University of East London.

Jones P (2015) New Care Models: empowering patients and communities - A call to action for a directory of support. Report for NHS England. https://www.england.nhs.uk/wpcontent/uploads/2015/12/vanguards-support-directory.pdf

Marmot M. Fair Society, Healthy Lives (The Marmot Review): A Strategic Review of Inequalities in England. London: University College London, 2010.

National Institute for Health and Care Excellence (2016) Community engagement: improving health and wellbeing and reducing health inequalities. NICE guidelines [NG44] London: NICE

O'Mara-Eves A, Brunton G, McDaid D, Oliver S, Kavanagh J, Jamal F, et al. (2013) Community engagement to reduce inequalities in health: a systematic review, meta-analysis and economic analysis. Public Health Res 2013;1(4)

Optimity Advisors (2015a) Community engagement - approaches to improve health and reduce health inequalities. Precis of the economic chapter of the EPPI Review (Component 1, Stream 3). Health Economics 1. Optimity Advisors.

Optimity Advisors (2015b) Community engagement - approaches to improve health and reduce health inequalities. Rapid review of economic evidence (Component 2, Stream 3). Health Economics 2. Optimity Advisors.

Optimity Advisors (2016) Community engagement - approaches to improve health and reduce health inequalities. Cost consequence analysis. Health Economics 3. Optimity Advisors.

Public Health England, NHS England (2015) A guide to community-centred approaches for health and wellbeing.

South J, White J, Gamsu M (2013) People-centred public health. Bristol: Policy Press.

Stokes G, Richardson M, Brunton G, Khatwa M, Thomas J (2015) Review 3: Community engagement for health via coalitions, collaborations and partnerships (on-line social media and social networks) a systematic review and meta-analysis. London: EPPI-Centre, Social Science Research Unit, UCL Institute of Education, University College London.

White J and Coan S (2016) Sadee Smile Evaluation - Final Report. Leeds: Centre for Health Promotion Research, Leeds Beckett University.

White J and Gamsu M (2015) Move patient and public involvement from the margins to the mainstream Health Service Journal December 2015 